\title{
MERCADO DE LEITE EM UMA CIDADE DE PEQUENO PORTE: COMPORTAMENTO DE CONSUMO E AVALIAÇÃO SENSORIAL
}

Bianca Viguini Chaves ${ }^{1}$, Suzana Maria Della Lucia $^{2}$, Mirela Guedes Bosi ${ }^{3}$, Tarcísio Lima Filho ${ }^{4}$, Aline Cristina Arruda Gonçalves ${ }^{5}$.

${ }^{1}$ Engenheira de Alimentos, Universidade Federal do Espírito Santo, Centro de Ciências Agrárias, Alegre-ES, Brasil.

2 DSc. Docente do Departamento de Engenharia de Alimentos, Universidade Federal do Espírito Santo, Centro de Ciências Agrárias, Alegre-ES, Brasil.

${ }^{3}$ DSc. Docente do Departamento de Engenharia de Produção, Universidade Federal do Espírito Santo, Centro Tecnológico, Alegre-ES, Brasil.

${ }^{4}$ DSc. Docente do Departamento de Engenharia de Alimentos, Universidade Federal do Espírito Santo, Centro de Ciências Agrárias, Alegre-ES, Brasil. (tarcisiolimaf@yahoo.com.br) ${ }^{5}$ DSc. Docente do Departamento de Engenharia de Alimentos, Universidade Federal de São João del-Rei, Campus Sete Lagoas, Programa Institucional de Bioengenharia, Sete LagoasMG, Brasil.

Recebido em: 08/04/2016 - Aprovado em: 30/05/2016 - Publicado em: 20/06/2016 DOI: 10.18677/Enciclopedia_Biosfera_2016_067

\section{RESUMO}

O leite ocupa lugar insubstituível na alimentação humana, devido ao benefício de seu consumo à saúde. Além disso, apresenta relevante papel econômico para os países produtores. Ainda que o Brasil seja o quinto produtor de leite do mundo, o consumo no país é menor do que o recomendado. Sendo assim, objetivou-se realizar um estudo de mercado de leite para entender o comportamento do consumidor na cidade de Alegre-ES, obtendo informações sobre o perfil dos consumidores, suas opiniões e atitudes frente às embalagens de tais produtos, além de informações sobre a aceitabilidade sensorial da bebida. Os resultados revelaram baixo consumo de leite pela população de Alegre, mesmo que a cidade esteja inserida em uma região produtora. Apesar de os consumidores afirmarem possuir uma marca de leite preferida, a aceitação sensorial de quatro marcas testadas mostrou-se igual para três delas. Preço, validade e marca são os atributos mais observados durante a compra do leite, e o estudo com embalagens nos grupos de foco revelou a importância que estas apresentam na decisão de compra do consumidor.

PALAVRAS-CHAVE: aceitação sensorial; grupo de foco; pesquisa de mercado.

\section{MILK MARKET IN A SMALL CITY: CONSUMER BEHAVIOR AND SENSORY EVALUATION}

\begin{abstract}
Milk plays an irreplaceable role for human nutrition due to its great health benefit. Moreover, it presents significant economic role for the producing countries. Although Brazil is the world's fifth-largest cow milk producer, consumption in the country is lower than the recommended daily intake. Therefore, the aim of this work was to study milk market in order to understand consumer behavior in the city of Alegre-ES, obtaining information on the profile of the consumers, their opinion and attitudes
\end{abstract}


towards the milk packaging, and information on the sensory acceptability. The results showed low milk consumption by the population of Alegre, although it is inserted in a milk-producing area. Even though the evaluated consumers presented preferred milk brand, sensory acceptance of four brands showed no difference for three of them. Price, shelf-life and brand are the most noted attributes for milk purchase, and the study on packaging with focus group revealed their importance on consumer purchase decision process.

KEYWORDS: sensory acceptance; focus group; market research.

\section{INTRODUÇÃO}

O leite é um alimento natural de alto valor nutritivo, sendo rico em cálcio, proteína e vitaminas A, B1 e B2 (EMBRAPA, 2011). O leite também possui relevante papel econômico para os países produtores. O Brasil é o quinto maior produtor de leite do mundo, com uma produção de 35,74 bilhões de litros no início de 2015 . A maior parte da produção concentra-se nas regiões Sul $(34,7 \%)$ e Sudeste $(34,6 \%)$, e Minas Gerais é o líder nacional, com aproximadamente 9,37 milhões de litros produzidos em 2014 (EMBRAPA, 2016). O Estado do Espírito Santo, em 2010, ocupou a $15^{a}$ posição na lista de produção anual de leite por estado, no Brasil. Entretanto, a produção anual de leite no Espírito Santo vem aumentando desde 2001 (EMBRAPA, 2013). De fato, a atividade de pecuária de leite contribui para a geração de renda de muitos produtores do estado e a produção de leite representou, em 2012, 1,4\% do volume nacional (IBGE, 2015).

Em relação ao consumo de leite no Brasil, ainda que este tenha aumentado nos últimos anos, de acordo com a Sociedade Brasileira de Alimentação e Nutrição, o consumo de leite e derivados pelo brasileiro ainda é menor do que o recomendado (SBAN, 2015). No que diz respeito especificamente ao leite, a Organização Mundial da Saúde (OMS) preconiza que crianças de até dez anos tomem $400 \mathrm{~mL}$ de leite/dia; o consumo deve ser maior para os jovens entre 11 e 19 anos, $700 \mathrm{~mL} /$ dia. Já para adultos e idosos, a OMS recomenda ingerir $600 \mathrm{~mL} /$ dia (BRASIL, 2016). Além disso, pesquisas revelam que o brasileiro consome em média $89 \%$ e $41 \%$ a mais de refrigerantes e cervejas, respectivamente, apresentando baixa ingestão de leite (EMBRAPA, 2011).

Devido a esse cenário contraditório da produção e consumo de leite no país, faz-se de importância um estudo buscando entender as razões para o consumo ou não consumo pela população, por meio da obtenção de informações sobre perfil demográfico, atitudes, opiniões, comportamentos, hábitos e aceitação sensorial do produto. Este estudo pode ser realizado por meio da Pesquisa de Mercado, ferramenta bastante empregada quando se pretende obter informações sobre expectativas de clientes e motivadores de consumo, além de outras informações que visam a quantificar e compreender as relações de consumo (GONÇALVES et al., 2013). Do mesmo modo, a utilização da pesquisa qualitativa denominada Grupo de Foco permite investigar pensamentos, opiniões e atitudes dos participantes de um grupo sobre os produtos e suas embalagens (DELLA LUCIA \& MINIM, 2013). Além disso, deve-se estudar como os consumidores avaliam o leite perante seus atributos de aparência, aroma, sabor e textura (características sensoriais), a fim de entender como estes atributos influenciam na aceitação do produto. Utilizando testes de Avaliação Sensorial do leite, pode-se também verificar a associação entre a avaliação das características sensoriais e aceitação e consumo.

Estando a cidade de Alegre entre os produtores leiteiros do Estado do Espírito Santo, situada em uma região que abrange tanto produtores quanto indústrias de 
laticínios, e devido a suas características sociais e demográficas heterogêneas, este município é objeto interessante para a realização de um estudo de mercado de leite. Dessa forma, pode-se mapear o mercado consumidor de leite em Alegre-ES, interpretando os desejos dos consumidores e as motivações que os levam a adquirir e a consumir esse alimento.

Sendo assim, objetivou-se realizar um estudo de mercado de leite em AlegreES, obtendo informações sobre o perfil dos consumidores de leite, suas opiniões e atitudes diante das embalagens de tais produtos, além de informações sobre a aceitação sensorial de amostras comerciais de leite.

\section{MATERIAL E MÉTODOS}

Este trabalho foi aprovado pelo Comitê de Ética em Pesquisa do Centro de Ciências da Saúde da Universidade Federal do Espírito Santo (CCS-UFES) sob o nำ123/11.

\section{Pesquisa de mercado}

Método de coleta de dados - O método de coleta de dados empregado foi uma pesquisa descritiva por meio da aplicação de questionário estruturado com questões de caráter exploratório. As questões (Quadro 1) foram formuladas com base em estudo anterior sobre perfil de consumidores de alimentos (ARRUDA et al., 2009) e conforme cuidados sugeridos por GONÇALVES et al. (2013) na formulação de questionários.

QUADRO 1 Resumo das questões elaboradas para o questionário da pesquisa de mercado

\begin{tabular}{|c|c|}
\hline \multicolumn{2}{|r|}{ CONTEÚDO DAS QUESTÕ̃ES } \\
\hline $\begin{array}{l}\text { Questões em comum } \\
\text { para todos os } \\
\text { entrevistados }\end{array}$ & $\begin{array}{l}\text { Sexo, idade, estado civil, grau de instrução, ocupação, } \\
\text { renda } \\
\text { Qual a bebida mais consumida? } \\
\text { Conhecimento e diferenças entre leite tipo A, B e C, } \\
\text { pasteurizado e UHT } \\
\text { Consome leite puro? }\end{array}$ \\
\hline $\begin{array}{l}\text { Questões específicas } \\
\text { para não consumidores } \\
\text { de leite }\end{array}$ & $\begin{array}{l}\text { Motivos de não consumo de leite puro? } \\
\text { Qual o substituto do leite? }\end{array}$ \\
\hline $\begin{array}{l}\text { Questões específicas } \\
\text { para consumidores de } \\
\text { leite/ leite puro }\end{array}$ & $\begin{array}{l}\text { Motivos de consumo de leite puro? } \\
\text { Conhecimento de benefícios do consumo de leite? } \\
\text { Formas de consumo de leite? } \\
\text { Com quais elementos relaciona o leite? } \\
\text { Características que gosta/não gosta no leite? } \\
\text { Qual o tipo de leite consumido (origem/diferentes } \\
\text { embalagens/quantidade de gordura)? } \\
\text { Quantidade de leite consumida? } \\
\text { Qual o horário de maior consumo do leite? } \\
\text { Qual o local de maior consumo do leite? } \\
\text { Quais atributos observa na compra? } \\
\text { Existe marca preferida? }\end{array}$ \\
\hline
\end{tabular}

Foi realizado um pré-teste após a elaboração do questionário, de maneira a verificar se as questões desenvolvidas, assim como o vocabulário empregado era adequado ao propósito do estudo, sem apresentar tendenciosidade ou ambiguidade. 
Para tanto, o questionário elaborado foi aplicado a um total de $10 \%$ da população amostral (GONÇALVES et al., 2013).

Universo de investigação e tamanho da amostra - $O$ universo de investigação deste estudo foi a cidade de Alegre-ES. A escolha baseou-se no fato de ser uma cidade situada em uma região que abrange tanto produtores de leite quanto indústrias de laticínios. De acordo com NASCIMENTO NETA et al. (2015), a cidade de Alegre - ES possui a produção de leite como principal atividade econômica da maioria da população rural ativa. Além disso, a cidade possui características sociais e demográficas que permitam uma abordagem heterogênea em relação à amostra (GONÇALVES et al., 2013). A cidade de Alegre possui 30.768 habitantes (IBGE, 2013) e se localiza no sul do Estado do Espírito Santo. Como a população está entre 20.000 e 50.000 habitantes, o município é considerado de pequeno porte II (BRASIL, 2013).

Os questionários foram aplicados a transeuntes que circulavam próximo a supermercados, mercados e comércios de produtos alimentícios em geral. Portanto, a coleta de dados foi realizada utilizando uma amostra intencional aleatória, estatisticamente significativa (ARRUDA et al., 2009; DUTRA et al., 2013). Para a definição do tamanho da amostra a partir da população do município analisado, foi empregada a Equação 1 (GONÇALVES et al., 2013).

$$
n=q \cdot p \cdot Z^{2} \cdot\left(e^{2}\right)^{-1}
$$

em que: $n$ = tamanho da amostra; $Z$ = abscissa da distribuição normal em um nível de confiança pré-estabelecido; $p=$ proporção de ocorrência da variável em estudo na população; $q$ = 1-p; e = erro máximo admitido. Estabeleceu-se um erro amostral e $=0,06$ e um intervalo de confiança de 95\%. Dessa forma, o valor de $Z$ adotado foi de 1,96. Uma vez que o valor de $p$ não era conhecido, adotou-se $p$ igual a 0,5 (GONÇALVES et al., 2013) e, portanto, q igual a 0,5. Assim, o tamanho da amostra estabelecido foi de 267 indivíduos (extrapolado para 270), entrevistados no período de novembro de 2011 a fevereiro de 2012.

Análise dos dados - Os dados obtidos a partir da aplicação do questionário aos participantes foram tabulados e analisados utilizando-se a análise descritiva com a distribuição da frequência das respostas às perguntas, empregando-se histogramas e gráficos tipo pizza (GONÇALVES et al., 2013).

\section{Análise sensorial - Teste de aceitação}

O teste de aceitação ocorreu no Laboratório de Análise Sensorial do Centro de Ciências Agrárias da Universidade Federal do Espírito Santo (CCA-UFES). Esse teste foi realizado com amostras de leite de marcas comerciais encontradas no mercado de Alegre-ES. A definição do número de amostras e das marcas selecionadas para avaliação foi feita em função de respostas obtidas durante a pesquisa de mercado.

Foram recrutados 75 consumidores habituados ao consumo de leite. As amostras foram servidas em copos descartáveis de $50 \mathrm{~mL}$ codificados com números aleatórios de três dígitos. Cada julgador recebeu uma ficha de avaliação contendo uma escala hedônica de nove pontos (sendo atribuída nota 9 para o termo "gostei extremamente" e nota 1 para "desgostei extremamente") em que lhe foi solicitado que marcasse o seu julgamento em relação à aceitação da bebida, avaliando o aroma, o sabor e a aceitação global das amostras. Os resultados foram analisados por meio de análise de variância (ANOVA) e teste de Tukey (REIS \& MINIM, 2013). 


\section{Sessões de grupo de foco}

Foram realizadas três sessões de grupo de foco, em mesa redonda no Laboratório de Análise Sensorial do Departamento de Engenharia de Alimentos da UFES e de acordo com os procedimentos propostos por DELLA LUCIA \& MINIM (2013). No total, 19 consumidores participaram do estudo; a primeira sessão contou com seis participantes (quatro mulheres e dois homens), a segunda com sete (quatro mulheres e três homens) e a terceira sessão também contou com seis participantes (quatro mulheres e dois homens). O recrutamento dos participantes foi realizado utilizando questionário com perguntas relacionadas ao consumo de leite, hábito de frequentar supermercado e de ler o rótulo de produtos. Foram selecionados para participar do estudo apenas os participantes que frequentavam supermercados e consumiam leite regularmente.

Durante as sessões, objetivou-se investigar os pensamentos, opiniões e atitudes dos consumidores sobre o leite e sobre as embalagens de leite comercializadas em Alegre-ES. O moderador explicou o objetivo da sessão, solicitou permissão para filmagem das sessões e seguiu o roteiro de perguntas sobre o comportamento dos participantes durante suas compras e diante de embalagens de leite apresentadas durante a sessão. Algumas perguntas foram realizadas em relação à embalagem apresentada, como, por exemplo, perguntas abordando os termos "integral", "desnatado" ou "semidesnatado".

As embalagens utilizadas nas sessões de grupo de foco (Quadro 2) foram selecionadas a partir de respostas obtidas durante a etapa de pesquisa de mercado. Cada sessão teve duração média de 90 minutos. Os dados obtidos (por meio dos questionários dos participantes selecionados e das gravações e anotações das respostas) foram lidos e estudados, considerando as palavras utilizadas pelos consumidores, o contexto da pergunta e a especificidade das respostas. $\mathrm{O}$ grupo de foco é um método qualitativo, portanto, não foi realizada análise estatística; os dados foram analisados por distribuição de frequência das respostas, para fins de ilustração (DELLA LUCIA \& MINIM, 2013).

QUADRO 2 Descrição das embalagens utilizadas neste estudo

\begin{tabular}{|c|c|}
\hline Embalagem & Resumo da descrição da embalagem \\
\hline B & $\begin{array}{l}\text { Leite da marca B, em embalagem cartonada, sem tampa, com rótulo nas cores } \\
\text { verde, vermelho e amarelo, ilustração de sol, campo com árvores e flores (leite } \\
\text { UHT). }\end{array}$ \\
\hline C & $\begin{array}{l}\text { Leite da marca C, em embalagem cartonada na cor azul com listras azuis claras, } \\
\text { com ilustração de um copo de leite e com tampa Abre Fácil na cor branca (leite } \\
\text { UHT). }\end{array}$ \\
\hline D & $\begin{array}{l}\text { Leite da marca D, em garrafa plástica, com tampa preta, rótulo branco e } \\
\text { ilustração preta de uma vaca com um filhote (leite UHT). }\end{array}$ \\
\hline$E$ & $\begin{array}{c}\text { Leite da marca E, em embalagem plástica, rótulo com fundo azul e ilustração } \\
\text { dos demais produtos da marca (leite pasteurizado). }\end{array}$ \\
\hline $\mathrm{F}$ & $\begin{array}{l}\text { Leite da marca } F \text {, em embalagem cartonada, rótulo nas cores verde, amarelo e } \\
\text { azul. Tampa rosqueável. Ilustração de uma fazenda, com casas, plantação e } \\
\text { vaca (leite UHT). }\end{array}$ \\
\hline G & $\begin{array}{c}\text { Leite da marca G, em embalagem cartonada, com tampa rosqueável na cor } \\
\text { preta, com rótulo nas cores branca e vermelha, com ilustração de metade de um } \\
\text { coração vermelho (leite UHT). }\end{array}$ \\
\hline
\end{tabular}

Foram utilizados os programas Excel ${ }^{\Theta}$ e o software SAEG ${ }^{\Theta}$ no auxílio à análise dos dados provenientes da pesquisa de mercado, teste de aceitação e grupos de foco. 


\section{RESULTADOS E DISCUSSÃO}

\section{Pesquisa de mercado}

O pré-teste realizado com 27 entrevistados, após a elaboração do questionário, permitiu concluir que as questões desenvolvidas (Quadro 1), assim como o vocabulário empregado, eram adequadas ao propósito do estudo, sendo estas mantidas para a pesquisa de mercado propriamente dita. Na pesquisa de mercado, dos 270 entrevistados, 148 eram do sexo feminino $(54,8 \%)$ e 122 do sexo masculino (45,2\%), apresentando idade entre 18 e 79 anos. Um total de $36,7 \%$ dos participantes encontrava-se com idade entre 20 e 29 anos; $21,5 \%$ entre 30 e 39 anos; e 20,0\% dos entrevistados tinham entre 40 e 49 anos. A predominância da faixa etária de 20 a 29 anos se deve ao elevado número de universitários e graduados que moram na cidade.

De todos os participantes, $33,7 \%$ declararam ser solteiros e $53,3 \%$ terem união estável. A maioria dos entrevistados possuía ensino superior incompleto $(30,0 \%)$, seguido de ensino superior completo $(29,3 \%)$ e segundo grau completo $(23,7 \%)$. A grande percentagem de universitários e graduados reafirma uma característica dominante do município, no qual está inserido um Centro de uma Universidade Federal, um Instituto Federal de Educação, Ciência e Tecnologia e uma Faculdade Particular.

A ocupação dos entrevistados era variada, sendo 16,3\% dos mesmos autônomos e 14,8\% estudantes. No que diz respeito à renda dos entrevistados, $45,9 \%$ declararam possuir renda média entre um e três salários mínimos e $29,6 \%$ entre quatro e seis salários. Um percentual de 9,3\% dos participantes declarou possuir renda entre dez e 12 salários. Somente 7,0\% declararam renda acima de 13 salários mínimos.

Em relação ao comportamento de consumo, a água, o café e o refrigerante foram as três bebidas mais citadas (Figura 1). O refrigerante, além de ter sido citado neste estudo como sendo de alto consumo, é consumido pelos brasileiros, em média, $89 \%$ a mais do que o leite (EMBRAPA, 2011).

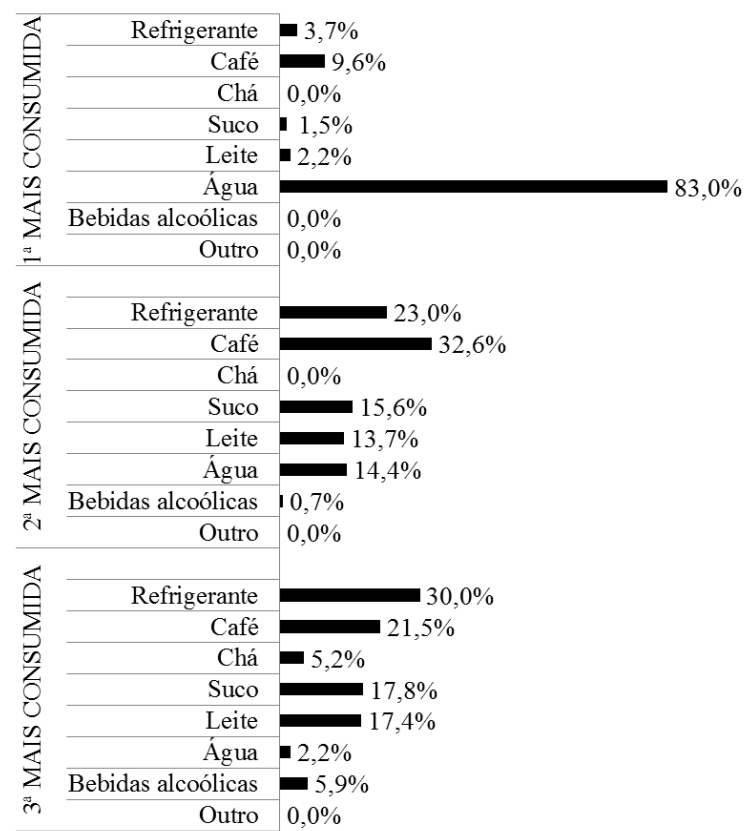

FIGURA 1 Bebidas preferidas para consumo pelos entrevistados, porcentagem. 
A água foi citada por $83,0 \%$ dos consumidores como sendo a bebida mais consumida. O café foi apontado por $32,6 \%$ dos entrevistados como a segunda bebida mais consumida e ocupou a segunda posição quando se refere à primeira bebida mais consumida (9,6\%). ARRUDA et al. (2009) desenvolveram um estudo dos motivadores do consumo e não consumo de café, observando que o café foi apontado como a primeira bebida mais consumida pelos entrevistados. Neste mesmo estudo, o leite não foi mencionado como a primeira bebida mais consumida; entretanto, $17,1 \%$ dos participantes afirmaram ser o leite a segunda bebida mais consumida por eles.

O presente estudo revelou o baixo consumo de leite pela população de Alegre, ocupando a quarta posição no que se refere à primeira bebida mais consumida $(2,2 \%)$. Isto é um fato interessante e contraditório, uma vez que a cidade de Alegre situa-se em uma região produtora de leite e apresenta baixo consumo do mesmo pela população.

Para o levantamento do conhecimento dos entrevistados a respeito do leite, os mesmos foram indagados sobre as diferenças entre os tipos de leite existentes no mercado. A maioria $(73,0 \%)$ declarou saber da existência de leite tipo A, B e C, porém somente $21,1 \%$ sabiam a diferença entre esses tipos de leite. Além disso, $74,1 \%$ dos entrevistados responderam não saber a diferença entre leite pasteurizado e leite UHT (Ultra High Temperature ou Ultra Alta Temperatura). Do total de entrevistados, $14,4 \%$ declararam não consumir leite de forma alguma. As principais bebidas citadas como substitutas do leite nas refeições foram o suco $(28,2 \%)$, o café $(28,2 \%)$ e a água $(15,4 \%)$.

Dos indivíduos que responderam consumir leite (um total de $85,6 \%$ dos entrevistados), 55,4\% declararam que não consomem leite puro, mas que consomem leite de alguma forma. Observou-se que os principais motivos apontados para não consumirem o leite puro foram não gostarem do sabor $(49,3 \%)$ e a falta de hábito $(37,5 \%)$.

Em relação às formas de consumo de leite, os entrevistados que não consomem leite puro, mas que o consomem de alguma outra forma citaram, na maioria, o leite com café $(23,6 \%)$, outros derivados do leite $(21,6 \%)$ e leite com achocolatado $(19,1 \%)$. Neste grupo de consumidores, os períodos citados onde ocorre consumo de leite com maior frequência foram o café da manhã $(46,1 \%)$ e o lanche da tarde $(41,4 \%)$. A maioria dos consumidores responderam consumir leite em ambiente doméstico (84,4\%), e uma parcela menor (13,3\%) afirmou que o consumo de leite ocorre nos ambientes de trabalho. Um total de $67,2 \%$ dos consumidores deste grupo afirmaram não ter uma marca de leite de sua preferência.

Um total de $44,6 \%$ dos entrevistados que consomem leite disseram que consomem o leite puro, e apontaram como principais motivos para consumo gostarem da bebida $(39,7 \%)$, por fazer bem à saúde $(30,4 \%)$ e por hábito $(21,1 \%)$. Uma pesquisa realizada pelo Centro de Conhecimento em Agronegócios em conjunto com a Faculdade de Economia, Administração e Contabilidade de Ribeirão Preto e a Universidade de São Paulo (FUNDACE, 2012) revelou resultado semelhante, em que se observou uma percepção de que o leite é bom para a saúde. Quando questionados a respeito de algum atributo que rejeitavam no leite puro, $98,1 \%$ dos entrevistados que o consomem responderam que não rejeitavam nenhuma característica da bebida e a maioria apontou o sabor como sendo o atributo que mais apreciavam no leite puro $(92,2 \%)$.

Além de consumir o leite puro, este grupo também consome o leite de diversas outras formas. As formas mais citadas foram o leite com café $(25,2 \%)$ e os 
derivados de leite (22,2\%), como manteiga, requeijão e queijos. Além destes, consomem também iogurte (18,2\%) e leite em vitaminas de frutas (16,9\%).

Para os entrevistados que consomem leite puro, o leite é consumido com maior frequência no período da manhã e no período da tarde, tanto o leite puro propriamente dito quanto as outras formas de consumo: 44,7\% afirmaram ter o maior consumo no café da manhã e $41,7 \%$ o consomem no lanche da tarde. Os períodos menos indicados para o consumo de leite foram após o almoço $(1,0 \%)$ e antes de dormir (3,0\%). O baixo consumo de leite após o almoço pode ser explicado pelo hábito cultural do brasileiro em consumir o "cafezinho" após as refeições (ARRUDA et al., 2009). O leite é visto como a "bebida do amanhecer", sendo a primeira opção de consumo para o café da manhã (FUNDACE, 2012).

O ambiente doméstico foi citado como o local de maior consumo de leite $(91,3 \%)$, seguido pelo ambiente de trabalho (8,7\%). As padarias, lanchonetes e cafeterias não foram citadas como ambientes onde ocorre consumo da bebida. Estes resultados foram semelhantes aos encontrados entre os entrevistados que não consomem leite puro.

Quando indagados sobre terem ou não alguma marca de leite de sua preferência, $59,2 \%$ dos entrevistados que consomem leite puro responderam que possuem uma marca preferida. Este resultado foi diferente daquele encontrado para os não consumidores de leite puro, os quais afirmaram que não possuem marca preferida. Sendo assim, observou-se que a marca pode influenciar o consumidor do município em estudo na decisão de compra do produto, ao menos no que se refere a consumidores de leite puro. Isto pode ser corroborado pelo fato de que esses consumidores afirmaram consumir o produto porque gostam da bebida e porque consideram o sabor como o atributo mais importante do leite. Dessa forma, a associação do produto a uma marca pode influenciar a decisão de compra pelo consumidor, se o mesmo já possui experiência prévia (positiva ou negativa) para com esta marca (PINHEIRO et al., 2010).

Os dados obtidos na pesquisa de mercado revelaram que o prazo de validade $(38,3 \%)$, o preço $(33,9 \%)$ e a marca $(16,8 \%)$ são elementos determinantes no momento da compra do leite para os indivíduos que consomem leite $(85,6 \%$ do total dos entrevistados). Com relação à quantidade de leite consumida por dia, $64,1 \%$ dos entrevistados consumidores de leite responderam consumir, em média, o equivalente a um copo de leite por dia (200 mL). Esta quantidade ingerida encontrase abaixo da recomendada pela OMS, que preconiza o consumo de $600 \mathrm{~mL}$ a 700 $\mathrm{mL}$ de leite para jovens, adultos e idosos (BRASIL, 2016). Um estudo realizado por TOMBINI et al. (2012) com agricultores da região oeste do Paraná também revelou que $1 / 3$ dos entrevistados consomem leite e derivados abaixo das recomendações de ingestão ou não consomem tais produtos, o que é um fato interessante, já que estes eram trabalhadores rurais e que teoricamente estariam mais próximos do local de produção do leite.

Em relação ao conhecimento sobre os benefícios e propriedades do leite, $74,4 \%$ dos entrevistados consumidores de leite alegaram que o seu consumo está associado à prevenção de osteoporose e 7,9\% acreditavam que estava associado à promoção de massa muscular. Em contrapartida, uma parcela de 16,1\% admitiu não saber nenhum benefício do consumo de leite. Desta forma, observou-se que uma parte considerável da população de Alegre consome o leite sem ter consciência de seus benefícios. O leite foi considerado por parte dos consumidores como sendo fonte de cálcio, de energia e de proteínas. Alguns consideraram o leite como sendo também fonte de vitaminas e minerais (Figura 2). 


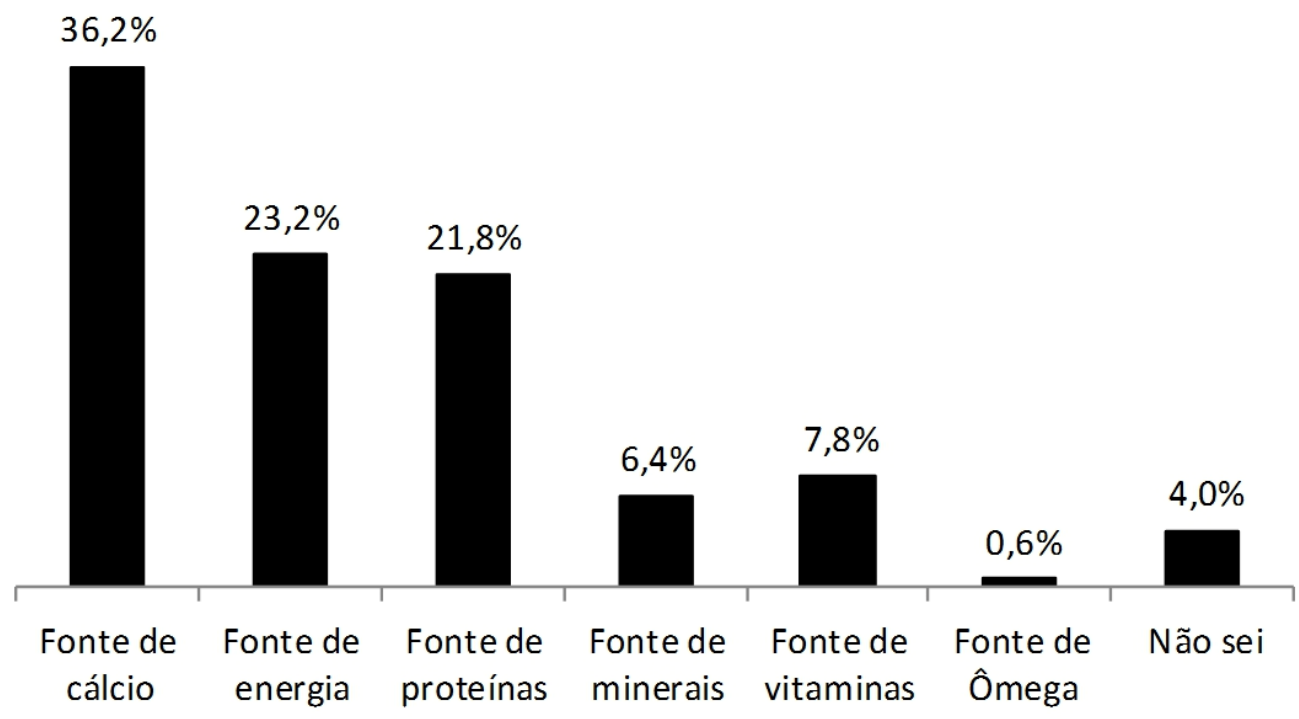

FIGURA 2 Frequência das respostas obtidas para a questão "você considera que o leite é...", expressa em porcentagem.

Todos os entrevistados que responderam consumir leite costumavam consumir leite de origem bovina. Apesar de ainda não haver o conhecimento por parte dos consumidores entrevistados sobre as diferenças entre o leite pasteurizado e o leite UHT, observa-se a preferência pelos leites UHT. A maioria dos entrevistados que consomem leite $(73,2 \%)$ respondeu consumir com maior frequência os leites "de caixinha" (UHT) e uma parcela menor (10,8\%) disse que ainda consome com mais frequência os "leites de saquinho" (pasteurizado). Ressalta-se que existem, ainda, indivíduos que consomem o leite cru, obtido de compra direta do produtor $(12,6 \%)$.

Em relação à preferência do consumidor quanto ao tipo de leite, mais da metade dos entrevistados consumidores de leite tem preferência pelo leite integral $(76,6 \%)$, seguido do leite desnatado $(18,2 \%)$ e do leite semidesnatado $(5,2 \%)$. Resultados semelhantes foram encontrados por MOLINA et al. (2010), em que a ordem de preferência encontrada para os tipos de leite foi a mesma. Ressalta-se que nenhum consumidor citou preferir os leites integral ou desnatado enriquecidos. Provavelmente isso se deve ao fato de a cidade em estudo não oferecer no mercado esses tipos de leite, levando a população a desconhecer, talvez, a existência e, portanto, a não consumi-los.

\section{Análise sensorial - Teste de aceitação}

Para aplicação do teste de aceitação sensorial, foram escolhidas quatro marcas comerciais de leite UHT integral. As marcas estão codificadas neste texto com as letras $A, B, C$ e $D$, sendo as marcas $A, B$ e $C$ escolhidas dentre as mais citadas na pesquisa de mercado. A marca $D$ foi escolhida em razão de ter sido recentemente inserida no mercado de Alegre, sendo objeto interessante de comparação com marcas já estabelecidas no mercado local. As marcas B, A e C, nesta ordem, foram as mais citadas pelos entrevistados que responderam possuir uma marca de leite preferida na pesquisa de mercado $(51,0 \%, 21,2 \%$ e $17,3 \%$, respectivamente, das citações dos respondentes).

A escolha por amostras de leite UHT integral também se deu em função das repostas obtidas na pesquisa de mercado, uma vez que o leite do tipo UHT e do tipo 
integral foram apontados como os mais consumidos pelos entrevistados. Sendo assim, os 75 consumidores (moradores da cidade de Alegre), 22 do sexo masculino e 53 do sexo feminino, com faixa etária entre 18 e 54 anos, avaliaram os atributos aroma, sabor (este apontado na pesquisa de mercado como o atributo mais apreciado no leite) e aceitação global de amostras das quatro marcas supracitadas. Pela ANOVA, observou-se diferença significativa entre as quatro marcas de leite, para todos os atributos analisados $(p<0,05)$. Na Tabela 1 estão resumidos os resultados do teste de Tukey.

TABELA 1 resultados do teste de Tukey para as quatro marcas comercias de leite UHT integral

\begin{tabular}{ccccc}
\hline \multirow{2}{*}{ Atributos } & \multicolumn{4}{c}{ Médias das Amostras* } \\
\cline { 2 - 5 } & $\mathrm{A}$ & $\mathrm{B}$ & $\mathrm{C}$ & $\mathrm{D}$ \\
\hline Aroma & $7,3 \mathrm{a}$ & $7,2 \mathrm{a}$ & $7,0 \mathrm{a}$ & $6,4 \mathrm{~b}$ \\
Sabor & $7,3 \mathrm{a}$ & $7,0 \mathrm{a}$ & $7,2^{\mathrm{a}}$ & $6,0 \mathrm{~b}$ \\
Aceitação Global & $7,3 \mathrm{a}$ & $7,1 \mathrm{a}$ & $7,3^{\mathrm{a}}$ & $6,3 \mathrm{~b}$ \\
\hline
\end{tabular}

*médias seguidas pela mesma letra, em cada linha, não diferem entre si, pelo teste de Tukey $(p>0,05)$.

As médias de aroma, sabor e aceitação global das marcas A, B e C situaramse entre os termos hedônicos "gostei moderadamente" (nota 7) e "gostei muito" (nota 8). Já as médias dos atributos da marca $D$ situaram-se entre os termos "gostei ligeiramente" (nota 6) e "gostei moderadamente" (nota 7).

Em geral, a aceitação das quatro marcas, para todos os atributos, foi boa. A marca $D$, recentemente lançada em Alegre, foi a menos aceita em todos os quesitos, - que pode ter sido causado pela falta de familiaridade dos consumidores participantes da avaliação sensorial para com esse produto.

\section{Sessões de grupo de foco}

A faixa etária dos participantes das sessões foi de 18 a 32 anos e $57,9 \%$ eram do sexo feminino. Dos 19 participantes, 78,9\% possuíam curso superior incompleto e $26,3 \%$ disseram ter renda familiar mensal de quatro a seis salários mínimos. Dos 19 consumidores, $31,5 \%$ sempre lêem rótulos dos produtos que consomem, $42,1 \%$ lêem frequentemente e $21,0 \%$ afirmaram ler, às vezes, os rótulos das embalagens. Os consumidores informaram no questionário aplicado que as principais características da embalagem observadas no momento da compra são preço, marca, embalagem e prazo de validade. DELLA LUCIA \& MINIM (2013) também observaram que o preço, a marca e a data de validade são de importância na decisão de compra.

As sessões de grupo de foco realizadas também indicaram que o preço, a marca e a embalagem são as características que mais interferem na intenção de compra dos consumidores. Muitos participantes mostraram-se fiéis a marcas tradicionais, evitando a compra de produtos de marca desconhecida.

MILAGRES et al. (2014) observaram a grande influência da embalagem de leite sobre a escolha do consumidor ao desenvolverem e estudarem embalagens para leite com concentração aumentada de melatonina, verificando que a embalagem pode contribuir de forma positiva ou negativa para a aceitação da bebida. As respostas obtidas para cada produto durante as sessões estão resumidas na Quadro 3. Os produtos das marcas B, C e D foram os mesmos utilizados no teste de aceitação sensorial. 
QUADRO 3 Resumo das respostas mais frequentes nas sessões de grupo de foco

\begin{tabular}{|c|c|c|c|c|c|c|}
\hline Característica & Produto B & Produto $\mathrm{C}$ & Produto D & Produto E & Produto F & Produto $\mathrm{G}$ \\
\hline Embalagem & $\begin{array}{c}\text { As cores são } \\
\text { muito } \\
\text { chamativas } \\
\text { e a } \\
\text { ilustração no } \\
\text { rotulo não } \\
\text { remete à } \\
\text { ideia de } \\
\text { leite. }\end{array}$ & $\begin{array}{l}\text { A cor clara } \\
\text { e neutra } \\
\text { agradou, } \\
\text { mas o } \\
\text { design não. }\end{array}$ & $\begin{array}{l}\text { Embalagem } \\
\text { bonita e } \\
\text { diferente } \\
\text { devido às } \\
\text { cores e } \\
\text { letras } \\
\text { utilizadas. }\end{array}$ & $\begin{array}{l}\text { A embalagem e } \\
\text { a ilustração não } \\
\text { são atraentes. }\end{array}$ & $\begin{array}{l}\text { Apesar de ser } \\
\text { muito colorida, } \\
\text { as cores da } \\
\text { embalagem são } \\
\text { harmoniosas. }\end{array}$ & $\begin{array}{c}\text { Apesar de } \\
\text { poucas cores, a } \\
\text { embalagem é } \\
\text { bonita e } \\
\text { chamativa. } \\
\text { Deveria conter } \\
\text { ilustração que } \\
\text { remetesse ao } \\
\text { leite. }\end{array}$ \\
\hline Praticidade & $\begin{array}{c}\text { O formato } \\
\text { da } \\
\text { embalagem } \\
\text { é prática } \\
\text { para } \\
\text { transportar e } \\
\text { armazenar, } \\
\text { porem não é } \\
\text { prática para } \\
\text { abertura. }\end{array}$ & $\begin{array}{c}\text { Apesar da } \\
\text { tampa Abre } \\
\text { fácil, esse } \\
\text { sistema não } \\
\text { apresenta } \\
\text { praticidade. }\end{array}$ & $\begin{array}{l}\text { Tampa } \\
\text { rosqueável } \\
\text { fornece } \\
\text { praticidade, } \\
\text { evitando } \\
\text { desperdício } \\
\text { do produto. }\end{array}$ & $\begin{array}{l}\text { Não apresenta } \\
\text { nenhuma } \\
\text { praticidade para } \\
\text { transporte, } \\
\text { armazenamento } \\
\text { e consumo. }\end{array}$ & $\begin{array}{l}\text { Devido à tampa } \\
\text { rosqueável, a } \\
\text { embalagem é } \\
\text { muito prática. } \\
\text { Seu formato } \\
\text { "fininho" traz } \\
\text { praticidade para } \\
\text { armazenamento. }\end{array}$ & $\begin{array}{l}\text { O formato da } \\
\text { embalagem é } \\
\text { prático somente } \\
\text { para } \\
\text { armazenamento } \\
\text { e transporte. }\end{array}$ \\
\hline Informações & $\begin{array}{c}\text { Apresenta } \\
\text { todas as } \\
\text { informações, } \\
\text { porém a } \\
\text { distribuição } \\
\text { das } \\
\text { informações } \\
\text { "polui" a } \\
\text { embalagem. }\end{array}$ & $\begin{array}{c}\text { As } \\
\text { informações } \\
\text { estão } \\
\text { dispostas } \\
\text { de forma } \\
\text { organizada } \\
\text { e fácil de } \\
\text { serem } \\
\text { localizadas. }\end{array}$ & $\begin{array}{c}\text { Informações } \\
\text { claras e } \\
\text { bem } \\
\text { distribuídas } \\
\text { na } \\
\text { embalagem. }\end{array}$ & $\begin{array}{c}\text { Pouca } \\
\text { informação a } \\
\text { respeito do } \\
\text { produto e } \\
\text { algumas se } \\
\text { desbotam } \\
\text { devido ao } \\
\text { material da } \\
\text { embalagem. }\end{array}$ & $\begin{array}{l}\text { As informações } \\
\text { são claras, } \\
\text { porém em } \\
\text { excesso. }\end{array}$ & $\begin{array}{l}\text { As informações } \\
\text { estão claras e } \\
\text { visíveis. }\end{array}$ \\
\hline Preço & $\begin{array}{l}\text { Não pagaria } \\
\text { mais por ela. }\end{array}$ & $\begin{array}{l}\text { Apesar da } \\
\text { tampa, não } \\
\text { pagaria } \\
\text { mais por } \\
\text { ela. }\end{array}$ & $\begin{array}{c}\text { Pagaria } \\
\text { mais } \\
\text { dependendo } \\
\text { do preço. }\end{array}$ & $\begin{array}{l}\text { Apesar de ser } \\
\text { um produto com } \\
\text { sabor mais } \\
\text { apurado, não } \\
\text { pagaria mais. }\end{array}$ & $\begin{array}{c}\text { Pagaria mais } \\
\text { pela } \\
\text { embalagem. }\end{array}$ & $\begin{array}{c}\text { Apesar da } \\
\text { embalagem } \\
\text { inovadora, não } \\
\text { pagaria mais } \\
\text { devido à falta da } \\
\text { tampa. }\end{array}$ \\
\hline
\end{tabular}

\section{CONCLUSÃO}

Apesar de apresentar importância na alimentação do brasileiro, o leite ainda é um produto que não ocupa posição de destaque entre as bebidas mais consumidas. A pesquisa de mercado aplicada revelou um baixo consumo de leite pela população de Alegre-ES. Isto é um fato interessante e contraditório, uma vez que Alegre situase em uma região produtora de leite e apresenta baixo consumo do mesmo pela população.

Apesar de parte da motivação do consumo do leite estar associada ao bem para saúde, uma parcela considerável da população entrevistada não sabia a quais benefícios o consumo de leite estava associado. Isso demonstra que, ainda existe uma tendência por parte dos consumidores em buscar informações a respeito dos produtos que consomem, isto não acontece com o leite.

Durante a compra do leite, nota-se que o preço e o prazo de validade são os atributos mais observados, seguidos pela marca. A maioria dos consumidores de leite apresenta uma marca preferida, sendo fiel a esta. Porém, com o teste de aceitação, foi possível observar que a fidelidade à marca é mais uma questão comportamental do que de preferência pelo produto em si. O teste revelou que três das quatro marcas apresentadas foram aceitas igualmente pelos consumidores. Isto mostra a importância de se conquistar o consumidor não somente pelo produto, mas pelos outros atributos associados à decisão de compra, como marca e embalagem. 
O resultado do estudo com as embalagens nas sessões de grupos de foco revelou que o consumidor tem buscado praticidade no manuseio e armazenamento do produto. Além disso, embalagens que apresentam ilustrações associadas a leite são preferidas pelos consumidores. Portanto, é preciso que a embalagem do leite apresente características relacionadas ao produto, além da praticidade como tampas e formatos compactos.

\section{AGRADECIMENTOS}

Ao Conselho Nacional de Desenvolvimento Científico e Tecnológico (CNPq) pela bolsa concedida.

\section{REFERÊNCIAS}

ARRUDA, A. C; MINIM, V. P. R.; FERREIRA, M. A. M.; MINIM, L. A.; SILVA, N. M.; SOARES, C. F. Justificativas e motivações do consumo e não consumo de café. Ciência e Tecnologia de Alimentos, Campinas, v. 29, n. 4, p. 754-763, 2009. Disponível em: <http://dx.doi.org/10.1590/S0101-20612009000400009>. Doi: $10.1590 /$ S0101-20612009000400009

BRASIL. Ministério do Desenvolvimento Social e Combate à Fome. Institucional. 2013. Disponível em: <http://www.mds.gov.br/falemds/perguntasfrequentes/assistencia-social/psb-protecao-especial-basica/cras-centro-dereferencias-de-assistencia-social/cras-institucional>. Acesso em: 28 jun. 2013.

BRASIL. Portal Brasil. 2016. Disponível em: <http://www.brasil.gov.br/economia-eemprego/2015/03/ministerio-da-agricultura-quer-fomentar-o-consumo-de-leite>.

Acesso em: 19 abr. 2016.

DELLA LUCIA, S. M.; MINIM, V. P. R. Grupo de foco. In: MINIM, V. P. R. (Ed.) Análise sensorial: estudos com consumidores. $3^{\mathrm{a}}$ ed. Viçosa, UFV. 2013. p. 82106.

DUTRA, L. B.; DUARTE, M. S. L.; SOUZA, E. C. G. Tendência do perfil dos consumidores de azeite de oliva. Revista do Instituto Adolfo Lutz, São Paulo, v. 72 , n. 4, p. 322-326, 2013. Disponível em: <http://revistas.bvsvet.org.br/rialutz/article/view/22899/23752>.

EMPRESA BRASILEIRA DE PESQUISA AGROPECUÁRIA (EMBRAPA). 2011. Disponível em: <http://www.cnpgl.embrapa.br/>. Acesso em: 09 mai. 2011.

EMPRESA BRASILEIRA DE PESQUISA AGROPECUÁRIA (EMBRAPA). 2013. Disponível em: <http://www.cnpgl.embrapa.br/>. Acesso em: 06 nov. 2013.

EMPRESA BRASILEIRA DE PESQUISA AGROPECUÁRIA (EMBRAPA). 2016. Disponível em: <https://www.embrapa.br/gado-de-leite>. Acesso em: 19 abr. 2016.

FUNDAÇÃO PARA PESQUISA E DESENVOLVIMENTO DA ADMINISTRAÇÃO, CONTABILIDADE E ECONOMIA (FUNDACE). Tomografia da cadeia do leite de ENCICLOPÉDIA BIOSFERA, Centro Científico Conhecer - Goiânia, v.13 n.23; p. 7912016 
São

Paulo.

2012.

Disponível

em: <http://www.fundace.org.br/leite/arquivos/tomografia/pesquisa_leite_consumidor.pdf >. Acesso em 15 ago. 2012.

GONÇALVES, A. C. A.; FERREIRA, M. A. M.; MINIM, L. A.; MINIM, V. P. R. Pesquisa de mercado aplicada à indústria de alimentos. In: MINIM V. P. R. (Ed.) Análise sensorial: estudos com consumidores. 3ํㅡㄹ ed. Viçosa, UFV. 2013. p. 231274.

INSTITUTO BRASILEIRO DE GEOGRAFIA E ESTATÍSTICA. Censo Demográfico. 2015. Disponível em: <http://www.ibge.gov.br>. Acesso em: 19 abr. 2016.

INSTITUTO BRASILEIRO DE GEOGRAFIA E ESTATÍSTICA. Espírito Santo Alegre - Infográfico. 2013.2 Disponível em: <http://www.ibge.gov.br/cidadesat/painel/painel.php?codmun=320020\#>. Acesso em: 06 jun. 2013.

MILAGRES, M. P.; MINIM, V. P. R.; SIMIQUELI, A. A.; ESPESCHIT, A. C. R.; MINIM, L. A. Fatores da embalagem de leite com concentração aumentada de melatonina na intenção de compra do consumidor. Revista do Instituto de Laticínios Cândido Tostes, Juiz de Fora, v. 69, n. 1, p 25-36, jan/fev., 2014. Disponível em: <http://dx.doi.org/10.14295/2238-6416.v69i1.303>. Doi: 10.14295/2238-6416.v69i1.303

MOLINA, G.; PELISSARI, F. M.; FEIHRMANN, A. C. Perfil do consumo de leite e produtos derivados na cidade de Maringá, Estado do Paraná. Acta Scientiarum. Technology, Maringá, v. 32, n. 3, p. 327-334, 2010. Disponível em: $<$ http://dx.doi.org/10.4025/actascitechnol.v32i3.3630>.

Doi:

10.4025/actascitechnol.v32i3.3630

NASCIMENTO NETA, F. C.; JUNQUEIRA, M. S.; CARNEIRO, J. C. S.; RAMOS, M. P. P.; ABDALLAH, F. R.; FRACALOSSI, C. P. Condições de produção de leite em propriedades familiares localizadas no município de Alegre - ES, Brasil. Revista do Instituto de Laticínios Cândido Tostes, Juiz de Fora, v. 70, n. 3, p. 117-131, mai/jun, 2015. Disponível em: <http://dx.doi.org/10.14295/2238-6416.v70i3.347>. Doi: $10.14295 / 2238-6416 . v 70 i 3.347$

PINHEIRO, R. M.; CASTRO, G. C.; SILVA, H. H.; NUNES, J. M. G. Comportamento do consumidor: pesquisa de mercado. $3^{a}$ ed. Rio de Janeiro, FGV, 2010. 164 p.

REIS, R. C.; MINIM, V. P. R. Testes de aceitação. In: MINIM V. P. R. (Ed.) Análise sensorial: estudos com consumidores. 3ª ed. Viçosa, UFV. 2013. p. 65-81.

SOCIEDADE BRASILEIRA DE ALIMENTAÇÃO E NUTRIÇÃO (SBAN). A importância do consumo de leite no atual cenário nutricional do brasileiro. 2015. Disponível em: <http://sban.cloudpainel.com.br/source/SBAN_Importancia-doconsumo-de-leite.pdf>. Acesso em: 19 abr. 2016. 
TOMBINI, H.; DALLACOSTA, M. C.; BLEIL, R. A. T.; ROMAN, J. A. Consumo de leite de vaca e derivados entre agricultores da região oeste do paraná. Alimentos e Nutrição, Araraquara, v. 23, n. 2, p. 267-274, abr./jun 2012. Disponível em: <http://serv-bib.fcfar.unesp.br/seer/index.php/alimentos/article/viewFile/2013/1249>. 